\title{
THE CRUSH SYNDROME IN COAL MINERS
}

\author{
G. Bentley, Oxford, and T. E. Jeffreys, Oswestry, England
}

From the War Memorial Hospital, Wrexham, North Wales

In 1941 Bywaters and Beall described a syndrome found in sixteen civilian victims of the aerial bombardment of London. The condition was described thus: "The patient has been buried for several hours with pressure on a limb. On admission he looks good except for swelling of the limb, some local anaesthesia and whealing. The haemoglobin, however, is raised, and a few hours later, despite vasoconstriction, made manifest by pallor, coldness and sweating, the blood pressure falls. This is restored to pre-shock level by (often multiple) transfusions of serum, plasma or, occasionally, blood. Anxiety may now arise concerning the circulation of the injured limb, which may show diminution of arterial pulsation distally, accompanied by all the changes of incipient gangrene. Signs of renal damage soon appear, and progress, even though the crushed limb be amputated. The urinary output, initially small, owing perhaps to the severity of the shock, diminishes further. The urine contains albumen and many dark brown or black granular casts. These later decrease in number. The patient is alternately drowsy and anxiously aware of the severity of his illness. Slight generalised oedema, thirst and incessant vomiting develop, and the blood pressure often remains slightly raised. The blood urea and potassium, raised at an early stage, become progressively higher and death occurs comparatively suddenly, frequently within a week. Necropsy reveals necrosis of muscle and, in the renal tubules, degenerative changes and casts containing brown pigment."

This was the first comprehensive account of a condition which had previously been observed in victims of the Messina earthquake in 1909, and in German victims of Allied air raids in the first world war (Colmers 1909; Frankenthal 1916, 1918). Bywaters and Beall called the condition "the crush syndrome," although Bywaters later expressed a preference for the title "ischaemic muscle necrosis" (Bywaters and McMichael 1953). Necrosis of muscle was the common etiological factor in all the cases described, and the pigment was found to be myohaemoglobin. In its natural history the condition after the injury has occurred resembles the anuria which follows muscle necrosis from any interference with the arterial blood supply by trauma or surgery, or the anuria associated with the toxic states of severe burns or septic abortion, which types of anuria are more common in peacetime than the classical crush syndrome.

The case histories of three patients buried in a coal mine by a fall of rock are presented here, and the pathogenesis of the condition and methods of management are discussed. The patients were trapped together for the same duration and arrived in hospital together. They illustrate the variation that can occur in the severity of the syndrome.

\section{CASE REPORTS}

Case 1-A man aged forty-three years was buried face downwards for seven hours, but his head and neck were not covered. He remained conscious and in good spirits throughout this time. Morphia had been given to him while he was trapped. On arrival in hospital he was conscious and complaining of numbness, tingling and inability to move the left leg below the knee. The right hip was painful. He had not passed urine since the accident. The pulse rate was 80 per minute and the blood pressure 110/90 millimetres of mercury. There were abrasions over the chest, abdomen and right arm. Both thighs and calves were bruised and the skin was blistered over the anterior aspects of both legs. Both feet were warm and pink, both calves were slightly swollen and the posterior tibial pulse was felt on either side. Sensation was blunted over both feet and legs up to the mid-calf. Movement was present in all muscle 
groups except the long flexors and extensors of the left toes. Movement of the right hip was limited and painful, and radiographs revealed a comminuted trochanteric fracture of the right femur. There was no other bony injury to the legs, pelvis or spine.

The right leg was immobilised on a Thomas's splint without traction. Oral fluids were restricted to thirty millilitres hourly. Tetracycline ( 250 milligrams intramuscularly) was given every six hours: 500 millilitres of 10 per cent mannitol were given during three hours. His initial condition was satisfactory but after twenty-four hours he had not passed urine, began to vomit and became increasingly drowsy. Catheterisation yielded 350 millilitres of black urine which, on microscopic examination, was found to contain scanty red cells and

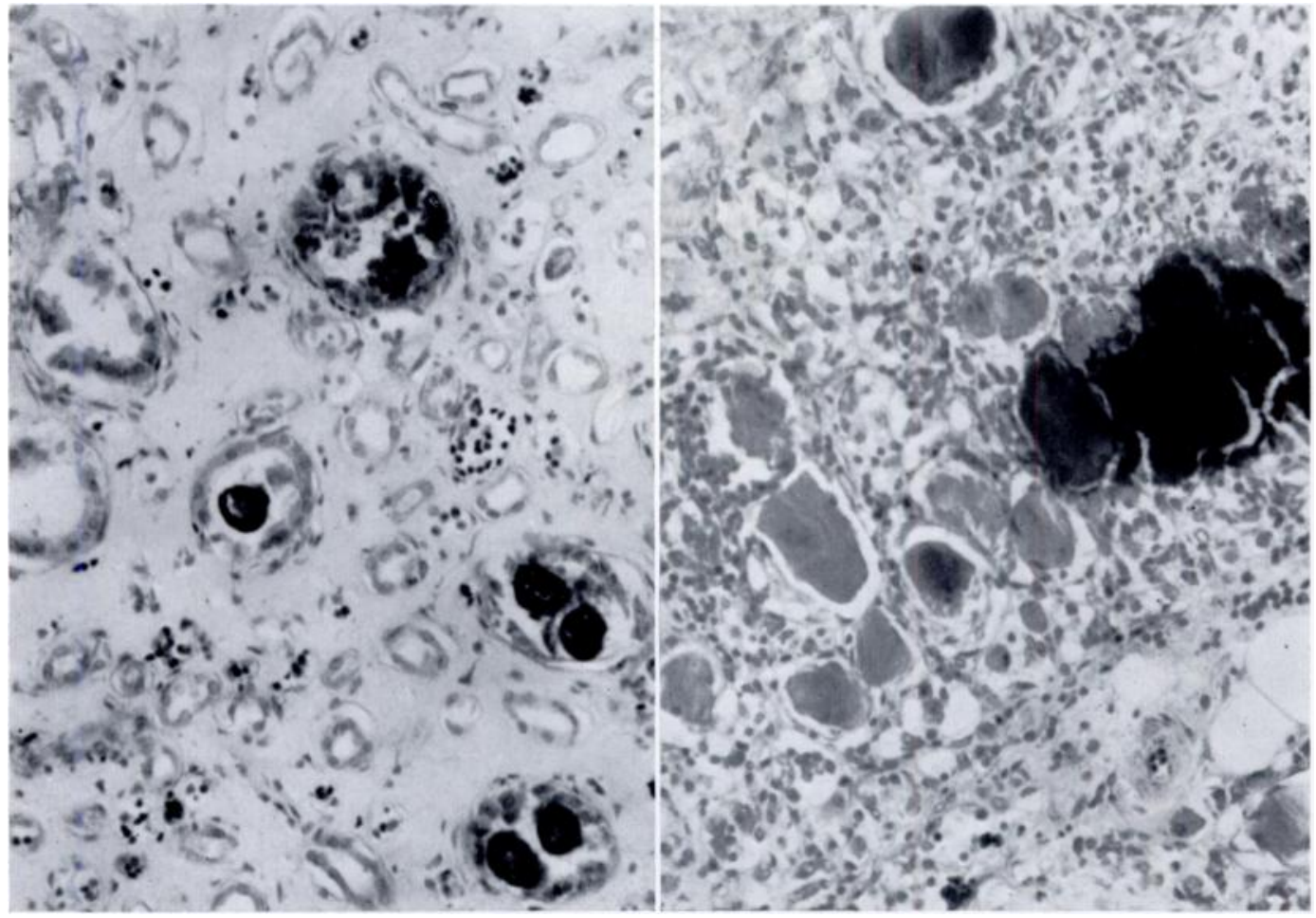

FiG. 1

FIG. 2

Case 1. Figure 1-Photomicrograph of section of kidney showing tubular epithelial degeneration and hollow pigment casts. (Haematoxylin and eosin, 28.) Figure 2-Photomicrograph of section of tibialis anterior showing necrosis and granulation. (Haematoxylin and eosin, $\times 28$.)

myohaemoglobin. At this time the haemoglobin was 132 per cent (19 grammes), the serum potassium was 8 milli-equivalents per litre, sodium 128 milli-equivalents per litre, chloride 96 milli-equivalents per litre, and the blood urea 138 milligrams per cent.

Forty units of insulin and 50 grammes of glucose were given intravenously, 30 grammes of an ion-exchange resin (Resonium A) were given per rectum and peritoneal dialysis was begun, using 1 litre of potassium-free solution (Dialaflex, Allen and Hanburys Ltd.). The fluid was run into the peritoneal cavity for thirty minutes, allowed to remain for one hour and then siphoned off. The dialysis was repeated and after six hours the patient's general condition had improved and he was less drowsy, but the left foot had become blue and cold, and the peripheral pulses could not be felt. The serum potassium had fallen to 6.4 milli-equivalents per litre, and the sodium had risen to 133 milli-equivalents per litre. A slow intravenous infusion of dextrose and 10 per cent calcium gluconate, containing 30 units of insulin in 250 millilitres was begun, and he was transferred to the Liverpool Artificial Kidney Unit. Repeated peritoneal and haemodialysis were performed during the next twenty-five days.

vol. $50 \mathrm{~B}$, No. 3, AUGUST 1968 
After six days the serum potassium was down to normal, but subsequently he developed pulmonary oedema on several occasions. On the twenty-fifth day he passed 250 millilitres of urine and was able to eat and drink. Twenty-four hours later he again developed acute pulmonary oedema and died in left ventricular failure. At necropsy the kidneys were found to be of normal size. Areas of cortical haemorrhage and radial streaky pallor were seen. The distal tubules showed epithelial degeneration and contained many pigment casts but no significant changes were seen in the glomeruli (Fig. 1). Section of the left tibialis anterior muscle showed necrosis with granulation and calcification (Fig. 2).

Case 2-A man aged thirty-five years had been buried from the neck down for the same duration as the patient in Case 1. On arrival at hospital he complained of tightness in both calves but appeared well otherwise. His pulse rate was 130 per minute, and the blood pressure 220/120 millimetres mercury. Both thighs and calves showed blistering of the skin. The calves were extremely swollen, tense and tender. Both feet were pale, though warm, and peripheral pulses were absent. Both legs were anaesthetic below the knee. Voluntary movement was absent from the flexors and extensors of the left ankle and foot but present on the right. Radiography revealed no bone injury. Soon after admission he passed 600 millilitres of dark brown acid urine which contained myohaemoglobin and a few red cells, but within a few hours the left foot became blue and cold. Under a general anaesthetic both calves were decompressed by incising the deep fascia from the popliteal fossae to the heels. In both legs the gastrocnemius bulged out under tension through the incision. When the deep fascia was opened the underlying muscle was pale but regained its normal colour on release. The anterior tibial compartments were also decompressed but swelling and pallor of muscle were not as startling as in the posterior compartments. After these procedures the peripheral pulses could be felt in both feet. Skin only was sutured. After operation the limbs were elevated and cooled with fans.

Intravenous mannitol, followed by dextrose saline, was administered but by the following day he had passed only 120 millilitres of dark brown urine and had begun to vomit. Catheterisation yielded a small quantity of very dark urine. By this time the haemoglobin was 120 per cent ( 17.4 grammes), the serum potassium was 8.2 milli-equivalents per litre, sodium 128 milli-equivalents per litre and blood urea 100 milligrams per cent. Resonium A, insulin and glucose were given as in Case 1, and peritoneal dialysis was carried out. This patient was obese and return of the dialysing fluid was difficult, despite the use of two catheters. Nevertheless within six hours the serum potassium had fallen to 6.3 milli-equivalents per litre and the electrocardiographic tracings were normal. The clinical condition was less satisfactory than the biochemical improvement suggested, and he remained drowsy. He was transferred to the Artificial Kidney Unit. Further attempts at peritoneal dialysis proved unsuccessful and repeated haemodialysis was necessary. Oliguria persisted until the sixteenth day when he passed 250 millilitres of urine. Further progress was satisfactory, although slight periorbital oedema and hypertension were still present seven weeks later. The decompression wounds broke down in their centre but healed after split-skin grafting. He has now returned to light surface work in the colliery, but has bilateral foot drop.

Case 3-A man aged forty years was crushed by the same fall of rock and for the same duration as the first two men, but only his legs were trapped. On arrival in hospital he complained of tightness of both calves. His general condition was excellent. Abrasions were present on both legs. The left calf was swollen and tense but there was no embarrassment of circulation to the foot. Movement and sensation were normal in this leg. The right calf was not swollen, the right foot was pink and warm and both pulses could be felt but there were patches of anaesthesia over the front of the leg and foot. All muscles contracted normally. Soon after admission he passed 40 millilitres of dark brown urine which contained myohaemoglobin and a few red cells. The serum electrolytic pattern was normal. 
His legs were elevated and cooled with fans. Sips of water were allowed by mouth, and intravenous mannitol followed by dextrose saline was given. Within twenty-four hours he passed 1,600 millilitres of dilute urine. The condition of the legs never gave rise to anxiety. Five days after admission the urinary output and content were normal. Mild ankle oedema persisted for some weeks but he returned to work on the pit surface within twelve weeks of injury. His only residual disability was limited dorsiflexion of the left ankle from contracture of the calf.

\section{DISCUSSION}

Incidence-Classical crush syndrome is rare in peacetime. Since the inception of the United Leeds Hospitals Renal Research Unit eight patients with crush syndrome have been treated there (Parsons 1966). The Birmingham Artificial Kidney Unit has treated seven such patients (Dawson 1966). It is likely to be seen in coal-mining areas more often than elsewhere because of the peculiar hazards of this occupation. Two cases have been reported from the Yorkshire coalfield (Scott 1962) and one from the South Wales mines (Williams 1966). Two other cases are noted in the National Coal Board medical service records (McLintock 1966). No case has been reported from the Nottingham mines (Nicoll 1966). We suspect that the true incidence is higher than these figures suggest and Harris (1941) observed that the injury was commonly seen on coalfields. The apparent rarity of the condition may reflect poor documentation of cases, and possibly more cases may be seen and recorded with the increased availability of specialised renal units.

Pathogenesis-After the initial reports in 1941 numerous explanations were postulated until it was shown that there was an association between necrosis of muscle and renal failure (Bywaters and Dible 1942). Myohaemoglobin released from crushed muscles was thought to become precipitated in acid urine producing physical blockage of the distal renal tubules (Baker and Dodds 1925). Bywaters thought that myohaemoglobin was deposited on the lining epithelium of that part of the tubules where acidification of urine takes place and prevented reabsorption of filtrate; in support of this he pointed out that pigment casts are invariably hollow (Bywaters 1944, Bywaters and McMichael 1953).

Loss of blood and plasma into the injured limb after release of pressure, producing prolonged hypotension and acute tubular necrosis, has been suggested as the cause of the renal failure. There is, however, no correlation between the degree of swelling of the limb and the level of shock, and exploration of the crushed limb-as in our patient-does not necessarily reveal an accumulation of blood (Scott 1962). Prolonged hypotension or crushing of an extremity produces prolonged arteriolar spasm and acute tubular necrosis in animals (Litwin, Walter and Jackson 1960). Repeated trauma to the limb of a dog can produce renal arteriolar contraction and renal ischaemia without systemic hypotension from a reflex passing to the autonomic supply of the renal pedicle (Powers, Boba, Shioya and Stein 1959).

Four possible factors may therefore contribute to the development of renal failure. Crushing of a limb induces renal arteriolar constriction and renal ischaemia. It has been shown experimentally that there is a correlation between the duration of crushing and the morbidity after release (Mehl, Paul, Hanashiro and Beattie 1964). After release, escape of fluid into the crushed limb may cause hypotension. This was not seen in our three cases. Myohaemoglobin released from damaged muscle is excreted by the glomeruli and produces tubular obstruction either because it causes physical blockage or because its deposition on the lining epithelium of the tubules interferes with reabsorption of filtrate, leading to a rise of intrarenal pressure (physiological resorption blockage). These factors may all contribute to the appearances of desquamation, fibrosis and necrosis of the cells in the ascending loop of Henle and the second convoluted tubule, with pigmented casts in the lumen of the tubules which together constitute the characteristic lesion of the crush syndrome.

Death occurs from renal failure. Hyperkalaemia, uraemia and acidosis follow oliguria, and within twenty-four hours of injury dangerously high levels of potassium are circulating

VOL. 50 B, NO. 3, AUGUST 1968 
in the blood. Damaged muscle, disintegrated red cells and the electrolytic shift of the catabolic response to injury all contribute to this hyperkalaemia. Other products of damaged muscle cannot be excreted. Ventricular fibrillation follows a rise in serum potassium above 8 milliequivalents per litre; low serum calcium produces tetany and cardiac arrhythmias. The serum sodium falls and the fluid retention can lead to pulmonary oedema. Unnecessary transfusion may aggravate this tendency.

\section{TREATMENT}

Prevention of renal failure-Peritoneal and haemodialysis have reduced the mortality of acute renal failure, but once renal failure has occurred an appreciable mortality still exists. Haemodialysis requires expert management in special units and carries the risk of complications which may be dangerous. Treatment should be directed towards the prevention of renal failure, as far as this is possible. The possibilities are discussed and a suggested scheme of management proposed.

General measures. Oral fluids and alkali before release-Myohaemoglobin is precipitated in the tubules in acid urine, or in that part of the tubule where acidification of filtrate occurs. It has been advocated that sodium bicarbonate should be given orally to produce an alkaline diuresis, and Bywaters (1944) suggested that two litres of bicarbonate solution should be given and suggested that release of the trapped patient might be delayed until this quantity had been swallowed. Intravenous infusion of sodium lactate might follow this. However, the renal arrest may have occurred while the patient was trapped and the only effect of ingesting large quantities of fluid may be to overload the circulation; also it is doubtful whether oral fluids are absorbed in any quantity under these conditions in any event. It is not justifiable to delay release of a trapped man in order to carry out treatment of doubtful value and possible hazard.

Osmotic diuretics - Crushing injury produces metabolic acidosis, and intravenous administration of the osmotic diuretic trishydroxymethyl aminomethane (T.H.A.M.) has been shown to diminish shock, myohaemoglobinuria and haemoglobinuria and renal failure following such injuries (Paul et al. 1965); also it buffers the acid metabolites produced from the dead muscle in the crushed limb and from the remaining dying cells after release of the limb. Early intravenous infusion of mannitol, also an osmotic diuretic, is said to be valuable in preventing renal failure (Luke, Linton, Briggs and Kennedy 1965). Luke employed the urinary urea to blood urea ratio in oliguric patients to decide which were likely to respond to treatment with mannitol. If the ratio is less than 14,100 millilitres of 20 per cent mannitol should be given intravenously in ten minutes and repeated in two hours if a 50 per cent increase in urinary output has not occurred. If no diuresis then occurs the standard regime for acute renal failure is instituted. The mechanism of action of mannitol is uncertain, and it should be given early if it is to be of any value.

Local measures-Should the crushed limb be amputated? In both world wars amputation was recommended as a valuable measure (Lancet 1959). The application of a tourniquet above the crushed area, and its subsequent slow release was thought to diminish the flooding of the circulation by toxic metabolites to a level at which they could be detoxicated by the liver (Eggleton 1942). A tourniquet does not prevent intraosseous venous return, but it has been shown experimentally that perfusion of the limb with dextrose before the release of a tourniquet reduced myoglobinaemia, haemoglobinaemia, myoglobinuria, haemoglobinuria, hyperkalaemia and acidosis (Thompson and Campbell 1959).

Amputation has not been shown to reduce the morbidity or mortality and it cannot be justified except as the only means of freeing a trapped man. The degree of crushing of a limb is not known until after release; our three patients were trapped for seven hours, yet no limb was destroyed. Perfusion of the limb after the application of a tourniquet is justifiable, provided that the tourniquet is applied just before release, and that rapid transfer to a hospital equipped 
and alerted to begin perfusion is possible. If such transfer takes longer than two hours the risk to the limb is not justifiable.

It is our opinion that no general or local measures have been shown to be sufficiently effective in preventing renal failure to justify any delay in release of the patient or his transfer to hospital.

\section{MANAGEMENT}

In view of these considerations we suggest that management be based on the following principles.

First aid-Morphia should be given to relieve pain and allay anxiety. (In our patients and in others of whom we have knowledge the fortitude of the trapped men was remarkable; but this fortitude is reinforced by the knowledge that the utmost efforts are being made to free them and that treatment has begun.) Oral fluids, unless contra-indicated by vomiting or suspected abdominal injury, may be given. Tourniquets or early amputation should not be employed as prophylactic measures against renal failure. The aim should be to release the patient and transfer him to a hospital unit ready for his reception as soon as possible.

General management-All patients who have been trapped are liable to renal failure. Careful clinical assessment of the general condition and of the state of the injured extremities provides a base line for subsequent observations. Hypovolaemic shock is treated by intravenous infusion in the usual way, particular care being taken to avoid overtransfusion. All urine passed should be measured and examined for myohaemoglobin, albumen, cells and casts. Estimation of serum electrolytes, urea and haemoglobin is done regularly. The bladder must be catheterised. If possible the ratio of urinary urea to blood urea is estimated. Mannitol is given intravenously, and if necessary repeated two hours later. If diuresis does not follow, a diagnosis of acute renal failure is made.

Management of acute renal failure-The blood urea, potassium, sodium and bicarbonate levels are estimated. An electrocardiographic tracing is made. These tests are repeated every eight hours. Any rise of serum potassium should be treated by administration of 30 grammes of Resonium A rectally, and the intravenous infusion of 40 units of insulin with 50 grammes of glucose. A carbon dioxide combining power of 15 milli-equivalents per litre or below should be corrected by intravenous lactate or bicarbonate solution. Anaemia is not likely to be a problem in the early stages but packed cell transfusion may be necessary later. Clinical signs of uraemia (confusion, delirium, hiccoughs and vomiting), a serum potassium level above 7.4 milli-equivalents per litre, and electrocardiographic evidence of myocardial intoxication are indications for dialysis. Peritoneal dialysis is simple, except in a fat patient, and effective. It will control hyperkalaemia before the patient is transferred to a unit where haemodialysis is available.

Management of the crushed limb-The crushed limb is treated by elevation and cooling to reduce its metabolic needs. Decompression is indicated if there are signs of increasing tension interfering with the circulation or the nerve conduction. Fascial compartments should be incised freely and any obviously dead muscle excised. Closure should be of skin only. It is better to close skin whenever possible, even although wound breakdown may necessitate later skin grafting.

\section{PROGNOSIS}

One of our three patients died. Peritoneal and haemodialysis are procedures fraught with complications and although the mortality rate of the crush syndrome has fallen since the introduction of the methods described, it remains high. There is a correlation between the duration of crushing and the extent of renal damage. Release of the trapped limb as soon as possible remains the most important measure in preventing renal damage. Prophylactic measures should be begun as soon as there is any suspicion of urinary suppression, which must be expected in any patient who has been crushed. The results of dialysis are not yet so good that there can be any complacency about management.

vol. 50 B, No. 3, AUGUST 1968 


\section{SUMMARY}

1. Three cases of traumatic anuria following muscle ischaemia ("crush syndrome") are reported.

2. The pathogenesis and treatment of the condition are discussed.

3. A scheme of management directed to the prevention of renal failure is proposed.

Our experience in the management of these three cases impressed on us how dependent the orthopaedic surgeon is on his colleagues in other disciplines when he is faced with a complex traumatic problem. It is with pleasure therefore that we take this opportunity of expressing our gratitude to Dr John Forbes, Consultant Physician, Dr David Parry, Medical Registrar, and Dr Lionel Wise, Consultant Pathologist, of the Wrexham Hospitals, for their advice and assistance in the management of these patients, to $\mathrm{Dr} \mathbf{H}$. J. Goldsmith, Consultant Physician of the Artificial Kidney Unit at Sefton General Hospital, Liverpool, for his cooperation and advice, and to the nursing staff and laboratory technicians of the War Memorial Hospital, Wrexham.

\section{REFERENCES}

BaKer, S. L., and Dodds, E. C. (1925): Obstruction of the Renal Tubules during the Excretion of Haemoglobin. British Journal of Experimental Pathology, 6, 247.

Bywaters, E. G. L. (1944): Ischemic Muscle Necrosis. Journal of the American Medical Association, 124, 1103. Bywaters, E. G. L., and Beall, D. (1941): Crush Injuries with Impairment of Renal Function. British Medical Journal, 1, 427.

Bywaters, E. G. L., and Dible, J. H. (1942): The Renal Lesion in Traumatic Anuria. Journal of Pathology and Bacteriology, 54, 111.

Bywaters, E. G. L., and McMichael, J. (1953): Crush Syndrome. In History of the Second World War: Surgery, p. 73. Edited by Z. Cope. London: Her Majesty's Stationery Office.

Colmers (1909): Ueber die durch das Ezdbeben in Messina am 28, Dec. 1908 verursachten Verletzungen. Archiv für klinische Chirurgie, 90, 701.

Dawson, R. L. (1966): Personal communication.

Eggleton, M. G. (1942): Crush Syndrome. British Medical Journal, 2, 495.

Frankenthal, L. (1916): Über Verschüttungen. Virchows Archiv für pathologische Anatomie und Physiologie, 222, 332.

Frankenthal, L. (1918): Die Folgen der verletzungen durch verschüttung. Bruns Beiträge zur klinischen Chirurgie, 109, 572.

Harris, H. A. (1941): Crush Injuries. British Medical Journal, 1, 491.

LANCET (1959): Averting the Crush Syndrome. Lancet, i, 928.

Litwin, M. S., WAlter, C. W., and JACKson, N. (1960): Experimental Production of Acute Renal Tubular Necrosis III, Acid Hematin-The Etiologic Pigment. Annals of Surgery, 152, 1016.

Luke, R. G., Linton, A. L., Briggs, J. D., and Kennedy, A. C. (1965): Mannitol Therapy in Acute Renal Failure. Lancet, i, 980.

McLintock, J. S. (1966): Personal communication.

Mehl, R. J., Paul, H. A., Hanashiro, P. K., and Beattie, E. B., Jun. (1964): Successful Treatment of Crush and Amputation Shock following Prolonged Periods of Ischaemia. Surgical Forum: Shock, p. 1.

Nicoll, E. A. (1966): Personal communication.

PARSONS, F. M. (1966): Personal communication.

Paul, H. A., Mehl, R. L., Schneewind, J. H., and Beattie, E. J., Jun. (1965): Shock in Replantation and Crush Syndrome: a Comparison of the Clinical Evaluation and Results of Treatment. Journal of Trauma, 5, 349.

Powers, S. R., Jun., Boba, A., Shioya, N., and Stein, A. A. (1959): Experimental Studies on Acute Tubular Degeneration following Crush Injury. Surgical Forum, 9, 62.

ScotT, R. W. (1962): Personal communication.

Thompson, W. W., and Campbell, G. S. (1959): Studies on Myoglobin and Hemoglobin in Experimental Crush Syndrome in Dogs. Annals of Surgery, 149, 235.

Williams, E. W. M. (1966): Personal communication. 